\title{
Rethinking How Humanities Think: Daring and "do / make / think"
}

\author{
Lindsay Parker \\ James Gifford \\ Fairleigh Dickinson University
}

\section{$\mathbf{W}_{\text {H }}$}

Hether the ADMinistrative organization of people in the humanities takes the form of a department of English, philosophy, history, or comparative literature, etc., in the modern university, humanistic disciplines continue to reflect the institution in which they reside, even as that institution submits them to "two cultures," "science wars," or corporatization. Neither disciplinary distinctiveness, group identity, nor solidarity within the humanities as a division protect these forms of inquiry and exchange against dominant institutional imperatives and incursions. As a traditional container for academic activity, departments contribute to what is increasingly becoming a black box nexus of activity around the individual players: the black box being a reduction of a complex process to simply its inputs and outputs with the box around process itself. ${ }^{1}$ That is to say, academics are deeply sensitive to administrative inputs, and

1 The black box concept is part of science and technology studies' sociology of scientific knowledge, initiated in large part by Bruno Latour and Michel Callon. Latour's narrowing of the notion conceives of a black box as the reduction of a process to inputs and outputs without a continuing sense of or attention to the internal processes that make the transformation of inputs to outputs possible. The crucial problem for Latour is the reduction of various actants (processes,

ESC 38.1 (March 2012): 89-113 
LINDSAY PARKer recently completed her doctorate at the University of Alberta and is equally active in comparative literature and science and technology studies. She has been a Lecturer at Simon Fraser University and has taught as a sessional at institutions across Western Canada.

Her research looks closely at the (dis) connections between medical and legal authority and cultural representations. these are manipulated to produce or bring about particular effects, or outputs. Inputs may encompass, for instance, faculty organization, salaries, teaching loads, or office allocations, while outputs can refer to the set of intellectual skills students acquire while completing a program, as well as advancements of knowledge through research (or in the corporate university, the mobile, skilled labour pools such subjects represent and the technologies they produce for markets). The problem, however, is what occurs within this black box: not simply what goes in and what comes out. The black box's metaphorical function excludes how our inputs lead to outputs by punctualizing ${ }^{2}$ the processes within it, yet this creates asymmetrical power relations among the stakeholders. The university becomes the metaphorical substitute for the human agents within it, and we begin to anthropomorphize the institution itself. However, if institutions confer identity by providing cohesion and systems of analogy, we cannot step outside of these institutional contexts in order to understand how the people within them contribute or take part. When we consider the role the university plays in our communities, how we struggle within the institution, or how the institution is changing its vital role in our transforming world, we must look in detail at the punctualized or black-boxed processes themselves. We, as the people within the institution, are vitally concerned with the human interactions, the struggles for employment, the success of

individuals, nonhuman participants, Nature, and so forth) to an input and an expected output, primarily because attention to these processes is either too complicated or continuously challenges accepted norms. Hence, the modern laptop is often conceived as a black box or, for computer programmers, an operating system can also be seen in the same way, such that thinking through a particular process still leaves others processes (both human and non-human) necessary to the full functioning of the machine as assumed inputs and outputs that are not considered. Baking bread or granting a T2202A tax form to students both employ a black box that bonds inputs to expected outputs while excluding key processes from consideration.

2 Much akin to the black box, "punctualization" occurs when the various inputs and outputs are unified such that actors can be considered a sum of other actors in a complex system that we need not open or understand in order to recognize-a keyboard and my computer screen are a complex system that I need not open in order to understand the relations among my inputs and outputs, which is to say that complex system is "punctualized." The labour of non-academic staff and the extra-academic operations of the university are often punctualized, as are the actors involved in these processes. They are reduced to expected outputs from inputs while the process is itself closed in a black box. Punctualization, however, allows for conceptual errors, such as the division between individuals and the institutions within which they think.

90 | Parker and Gifford 
our students, or simply the feelings of kinship toward those with whom we share a lifelong endeavour. The questions at issue in this article, then, are: what process and what institutional thinking do we discover when we open this black box, and how is the depunctualization of the relations within a department necessary for solidarity?

\section{Institutions (do) Think}

Do institutions think or do their personnel do the thinking? The question is uncomfortable for academics because of the potential for a human/ non-human division that implies centrally automated inputs and outputs devoid of agency and co-operation inside our black box. Yet the academy is surely about much more than comfort zones; it is or should be still about the embrace and interrogation of discomfort.

Mary Douglas, in How Institutions Think, denies that institutions and the agents within them are amenable to a unidirectional analysis. Rather than relying on agents to think for it, the institution powerfully shapes (without fully determining) the thinking of individuals within it by generating frameworks of relations and analogy. No single direction of influence is sufficient to account for self-sustaining institutions. This approach to the university, especially to those in the humanities, is unsettling; we tend to heroically pit individuals against institutions rather than seeing them as mutually constitutive and interdependent. From a less heroic or ritually oppositional vantage, we can be understood to think by virtue of the institutional frames we maintain by doing the thinking for which a university stands. Douglas's consideration of how institutions think moves us beyond typical concerns over what institutions think. Her provocation suggests that institutions think insofar as they enable analogy and calibrate meaning, and we belong to an institution insofar as we adopt this think, which creates solidarity and understanding among our peers: our academic community. This shifts our understanding of actor-academics thinking in the university because the metaphor of an anthropomorphic university thinking for itself is no longer acceptable. Instead, we realize that the university's socially determined and constructed apparatus is distinct from mere consciousness alone, that we are not conscious of apparatuses of analogy but, rather, conscious through them.

Douglas voices the resulting discomfort by claiming, "The very idea of a suprapersonal cognitive system stirs a deep sense of outrage" (x). Nonetheless, pitting the individual heroically against the institution risks conceiving of departments of humanities as having minds of their own. However, in the humanities as elsewhere there must exist an agreed-upon

\section{JAMES GIFFord is}

Assistant Professor of

English and Director

of the University Core at Fairleigh Dickinson University. He is most active in transAtlantic modernist and twentieth-century literature, in particular anti-authoritarian poetry networks. He has been equally active in music performance and cultural studies. 
intellectual style ${ }^{3}$ that binds groups of individuals into a cohesive unit, individuals who then work toward collectively beneficial aims under a common sense of mission. Our peers, to a degree, bound the horizon of possibility for our individual thinking. In fact, this is precisely Douglas's concern:

Writing about cooperation and solidarity means writing at the same time about rejection and mistrust. Solidarity involves individuals ready to suffer on behalf of the larger group and their expecting other individuals to do as much for them. It is difficult to talk about these questions coolly. They touch on intimate feelings of loyalty and sacredness. (1)

This very co-operation, which allows the institution to exist, is built on trust, and at the same time the institution needs solidarity before it can claim coherence. Douglas clarifies that "true solidarity is only possible to the extent that individuals share the categories [social and institutional] of their thought" (8). However, this is a deeply problematic notion, as "it contradicts the basic axioms of the theory of rational behavior by which each thinker is treated as a sovereign individual" (8). Against this discourse of self-maximization, which is implicit in components of rational choice, "our intuition is that individuals do contribute to the public good generously ... Whittling down the meaning of self-serving behavior ... makes the theory vacuous" (9). In this context, trust and community within the university are troubled by the Enlightenment project that the institution serves insofar as it emphasizes reliance on those selfish components of rational choice "on which economic analysis and political theory are based" (9).

By thinking of individuals and institutions together, the crux of our concern lies in the contrast between thinking solidarity and acting on mistrust, or making loyalty while doing distrust. Like most people in a particular kind of institution, we find that the thinking, doing, and making differ and hence give the appearance of being irrational in their conflicts. The varieties of such conflicts and their nature in the modern university

3 Ludwik Fleck, in his Genesis and Development of a Scientific Fact, discusses how thought collectives have prevailing thought styles. A "thought collective" he defines as "a community of persons mutually exchanging ideas or maintaining intellectual interaction," whereas a "thought style" is developed through the carrier-action of the thought collective in its capacity to provide or develop a given stock of knowledge and level of culture (Fleck 39). 
give our argument its focus, the humanities in Canadian universities in particular, and we speak from experiences in the West. ${ }^{4}$

\section{do / make / think}

What, then, is the think of a department, and how is this thought process inconsistent if not contradictory? The phrase "do / make / think" from Sandra Jeppesen (64) provides us with a formula for dialogue among activity, theorizing, and production. The unity of the three is key. However, we may encounter tensions or contradictions among "do / make / think" even when they ostensibly function for the same purpose. In a sense, these discrepancies reveal the conflicted unconscious of the university through an institutional parapraxis. Jeppesen argues

rather than a binary, i'd like to use a trilogy_do / make / think, [... which] is comprised of an analysis of and resistance to the many types of oppression we struggle against: sexism, heterosexism, imperialism and colonialism, racism, environmental destruction, capitalism, ableism, etc. it is comprised of our political ideas and the way we use them to transform our lives and the lives of others. $(64,73)$

Jeppesen emphasizes quotidian and institutionalized life as well as the "do / make / think" that may resist it. Yet, institutions confer identity, reflect forms of solidarity, and construct forms of sameness, or for Douglas, such forms of identity and sameness come to exist by virtue of things existing within the context of institutions because "sameness is not a quality that can be recognized in things themselves; it is conferred upon elements within a coherent scheme" (59).

Hence, institutions are founded on analogy, which confers identity and develops forms of discourse. This should discourage us from pointing to a single individual or a single action as uniquely or disproportionately culpable in the institution's construction and contrivance. We are all complicit in the doing, making, and thinking of the university and its various subcultures, such as humanities departments, programs, or faculties. An institution cannot possess a mind of its own, nor can it achieve coherence

4. We must also acknowledge the origins of our thoughts on this topic. We are grateful to the Humanities Research Unit for inviting Lindsay Parker to speak on "Rethinking the Humanities: Playing it Safe in Comparative Literature" for the "Re-Thinking the Humanities" symposium, 13-14. April 2011, and Inquire: Journal of Comparative Literature for inviting James Gifford to contribute " $U$ Views: A Report on the University in Canada" in January 2011. 
of its own accord. We must adopt its think and act out its do in order to make its objectives and bring about its existence distinct from the legal construct that endows it with being and the material objects that testify to its persistence. Legal constructs change and buildings may turn to new purposes or tenancies. ${ }^{5}$ Meanwhile, the university persists through the thinking and doing of its members. In this, we notice the human problem. We casually, or through administrators' repeated urgings, conceive of the university as a separate entity from the departments that contribute to its perpetuation and the individuals within those departments who call the university into existence through their activities. In turn, we equally casually regard the same individuals as thinking on their own or even resisting their departments or university without noticing how institutional schemas confer meaning and thereby shape the exercise of reason that leads them to resist. This division is alienating and elides the implicit solidarity.

\section{University Thinking}

How, then, do these institutions think? How do humanities departments think? What keeps the graduate student, the sessional instructor, and the faculty (as well as the staff, undergraduate students, and other stakeholders) in a state of solidarity that each individually may find so deeply isolating? Why such a contradiction between solidarity and isolation? What conflict creates alienation in the midst of solidarity? In other words, what is inside the unity of a department, college, faculty, or program? If we parse what comprises a department, at least in the humanities today, the divisions may suggest internal disunity. Yet, departments in the humanities are exceptionally coherent institutionally speaking, although this counts for little with some insiders. They seem reluctant to concede that the coherence of several hundred years (or even fewer than 100 months $^{6}$ ) incites a logic of its own, a manner of thinking all its own, which appears divisive to the individuals doing their own thinking as a part of this coherent

5 If the Hudson's Bay Company building in Edmonton can become the University of Alberta, or if a Vanderbilt estate can become Fairleigh Dickinson University, why not the reverse process? Edinburgh Napier University, in Scotland, has experienced this process on its Craighouse Campus, which was a psychiatric hospital, then a campus, and will soon become flats after the university vacates the facilities in 2013. Less dramatically, FDU sold its Rutherford campus to Felician College in 1993, and Fordham University sold the Marymount College campus to EF Education First (originally Europeiska Ferieskolan, European Holiday School) language schools in 2008.

6 Consider, for instance, the perpetuation of tradition in the "new" universities of British Columbia. 
apparatus: even our sense of internal strife is very often a part of institutional coherence. The concept of Two Cultures itself relies on a coherence achieved through analogies made possible by the institution within which these two cultures may be at war. Rationally, we feel this is impossible, and even so somehow we have come to assume within individual departments the role of authority in the midst of enlightenment-that is, we exercise power in the name of reason, but these exercises themselves contradict reason. These views are incompatible: authority and enlightenment. It is increasingly obvious that the modern university has adopted a mode of thinking fraught with contradictions that edge us ever closer to the surface of its conflicts and shifting function. We rely on inputs to achieve outputs without considering the punctualized process. This is especially so for the praxis-informed enlightenment epistemologies and critical engagement of the institution.

These conflicts are pressed ever closer to open disputes when modern humanities departments, whose critical praxis and epistemological undertakings connect so resolutely to Enlightenment precepts, assume an authority that extinguishes the individual exercise of rational thought and autonomy of action by relying on authority rather than reason. In this way, we are, in our unthinking praxis, in the midst of rethinking the Enlightenment, as Horkheimer and Adorno suggested we rethink the alienation from nature engendered in the Enlightenment project and instrumental reason. Is academic freedom so fragile? Can we enlighten the process of institutional thinking? Can we rethink the humanities in a frame amenable to itself? Regardless of the answers or evasions to such questions, it seems that the tension between academia and alienation will compel change just as surely as how universities think is a consequence of social conditions.

But these are grand and general phrases for a simple and specific problem. What happens when a university, or a humanities department, or a faculty does differently from its think? What is made from such conflicts, and how does it relate to Douglas's sense of "cooperation and solidarity" (1)? Let us say plainly, contradictions that display this alienation abound. For example, as institutions, universities exhort "excellence" as a key goal yet become "elite" by becoming the "largest" and recruiting the most sizeable student body. The doublethink of this "elite majority" is certainly something new and undoubtedly relates to recruiting foreign students, international fees, and the entrepreneurial impulse cultivated by the modern university either through its own recruitment from the corporate world or through governmental interventions in strategic funding. An institution that accepts a greater part of the public is not all bad, but it is

\section{It is increasingly}

obvious that the

modern

university has

adopted a mode

of thinking

fraught with

contradictions

that edge us

ever closer to

the surface of

its conflicts and

shifting

function. 
not elite nor is it achieving excellence in the typical meaning of those terms. Perhaps we ought not to wish it to. Nevertheless, the university is serving social ambitions as a branch of government: increasing the competitiveness of the Canadian workforce, shaping immigration policy, reinforcing international relations policy, returning to the ideological propaganda function of the media during the Cold War, decreasing recidivism in prison populations, and occupying an otherwise unemployed youth. These functions for the university, and Canadian universities in particular just now, is a return to the nationalist function of the university declared dead by Bill Readings fifteen years ago. We see Citizenship and Immigration Canada openly acknowledging education as an immigration pathway, ${ }^{7}$ despite conflicted provincial and federal jurisdictions, while it is also a struggle for the "hearts and minds" of international students as a part of foreign policy (perhaps most overtly with China and India at the moment). However, these activities are a turn from the rhetoric of excellence and reveal universities again doing something distinct from what they are thinking,

7 For instance, British Columbia's International Education Strategy states British Columbia must "encourage students who are studying skills needed in our economy, to stay here post-graduation" (British 25) and that access to student visas will develop by "pressing for improved opportunities for international student employment and residency in B.C., including through the Canada-B.C. Immigration Agreement" (25). By 2014, British Columbia plans to "increase opportunities for ... international students to move to permanent residency" (26). This entails increasing British Columbia universities' capacity during a period of austere budgets that see faculty positions vacant after retirements and continuing faculty substituted by term or sessional instructors. Hence, the provincial government will "pursu[e] private, public and not-for-profit partnerships to help meet capacity needs" (26). The focus becomes clear when the Canada-B.C. Immigration Agreement identifies international students under the same designation as "a temporary foreign worker" as a "Temporary Resident" (2.2.e). The function is the migration of capital and labour rather than promoting nationalist culture or the enlightenment project intrinsic in the development of reason through education, and hence the university's function is a pathway for immigration and the flow of capital, which conflicts with its institutional structure. The crux is the function of these pathways: either to educate in the exercise of reason, indoctrinate in national culture, or to regulate global migration and the transfer of labour and capital. If the expansion of "capacity" comes at the cost of a meaningful education for those students who pay the most, often for the least access to tenured instructors, then the ethics of the project must be reconsidered. If these students find admission by virtue of expansions to unaccredited satellite departments or facilities that house them in distinct buildings apart from the main student population, and if we find they are being disproportionately taught by the instructors who are paid the least while their students are paying the most (to facilitate a capital transfer), our evaluation must be dire-here is banking pure and simple, without a meaningful cultural or pedagogical function for the university. 
as if unconsciously fulfilling the aims of some other will foreign to their own intentions: a will that turns attention to public service and national ambitions (the university as a space) rather than only competition in a transnational marketplace (the university as a set of relations).

Universities, to be elite (regardless of whether this is desirable or not), must also be difficult. At the same time, administrative pressures and pedagogical ethics emphasize student retention and successful degree completion in a system of learning outcomes assessment and minimum achievement expectations. This is not what elite means. While we may like the meaning of this new idea, or at least components of it and its potentially student-centred focus on the public, we certainly cannot call it elite in the pursuit of excellence-we must find a better term for our mission in this regard. The university attempts to combine excellence with high retention and completion rates and the entrepreneurial expansion of degree offerings to ever-broader publics (which is an expansion of certification, not necessarily of education). We find here a culture of competition amidst a social group dependent on grade inflation and program evaluations based on completion and graduation rates. Indeed, contradictions in how the university thinks abound, as do motivations for these contradictions and impediments to their resolution. It is not, however, strictly a matter of the shifting policy implications of university activity in a return to nationalism, nation building, or international conflicts of ideology lived out by foreign and domestic student distinctions and international recruitment. Internal contradictions exist, particularly when public service conflicts with longheld traditions that are distinct from the entrepreneurial ambitions of the corporate university. ${ }^{8}$

8 Research and the construction of facilities for the public good stand out immediately as major functions of the university and, in many instances, far more funded functions than the support of students, who largely contribute to the cost of their own support. Given the increasing reliance on adjunct faculty, it is untenable to maintain that student tuition in Canada does not adequately recuperate instructional costs, which leaves ancillary resources shared with the research and public service function of the university, such as library resources, laboratory facilities, infrastructure, and so forth. Of course, the institution's own perpetuation is the true reason for its existence. 


\section{Dialogic Subjectivities in the Academy ${ }^{9}$}

I would like to identify my own reflexive position. I am a recently graduated doctorate in comparative literature from the University of Alberta, and I also just finished a faculty position as Limited Term Lecturer in World Literature at Simon Fraser University. It is no secret that departments of comparative literature are in decline, at least in Western Canada, although seemingly everywhere. The University of Alberta collapsed its formal Department of Comparative Literature into a program and merged it into the Office of Interdisciplinary Studies, which houses other humanities and interdisciplinary-focused programs, such as religious studies and humanities computing. It now appears poised to collapse it further. Despite its ever-shrinking operating budget, the program continues to thrive, notwithstanding other institutional challenges. UBC has also recently collapsed its comparative literature department, leaving its students to find a new home, again within interdisciplinary studies. More famously, the University of Toronto's graduate program in comparative literature very publically survived the budgetary gauntlet ("University" A5).

World literature, in stark contrast to its twin discipline, has become a popular new field for comparativists (not necessarily only of comparative literature) who have expanded, bypassed, or gone beyond their traditional European scope to include non-Western languages and approaches. Given that world literature courses have been part of the comparative discipline and its curricular structures for well over fifty years, it is not new so much as it is timely in this geopolitical climate. In fact, it occupies much the same position Gayatri Spivak accords to area studies due to its political origins and supports.
I also need to identify the socially determined component of my position as a subject within a highly ritualized institution with specific material conditions, practices, and organizational hierarchies. I am both an administrator and a junior faculty member in an American university that operates in Canada on a non-profit yet private basis, and this often sits uncomfortably in Canadian academic circles as a form of intellectual colonialism. The divisions are dizzying at times. My formal departmental affiliation is to one of the two campuses in the U.S., although a fourth campus has operated in the UK since 1965 when its premises and grounds were purchased from Trinity College, Oxford, the first fully-owned overseas campus of an American university. I am not yet tenured as faculty, yet hold in Vancouver the same administrative rank as my departmental director in America. I am a junior colleague with many of the academic responsibilities of the dean of my college delegated to me for my campus, which does not yet hold internal college status in the university as a whole. I am a Canadian scholar working in Canada, yet for research and funding, I am a foreigner abroad in both the U.S. and my country of birth. Oddly, were my institution to become for-profit or bound to the ideology of any number of transnational religious organizations, many of these classifying divisions would evaporate. Disciplinary divisions hold firm as well since I completed degrees in both literature and music, although I am director of an interdisciplinary program blending the arts and social sciences whose completion is mandatory for all students in all undergraduate programs on all campuses. To muddy matters further, I also teach in media and cultural studies, which under communications

9 Our inspiration for the dialogical format is Michael O'Driscoll and Edward Bishop's "Archiving 'Archiving'” (1-16). 
Yet, world literature's scope at SFU, where I have taught for the past three years, is also at stake because the program is in its infancy in Canada, and, crucially, it is not a department but a program: the very framework to which other departments have been collapsed.

These institutional frames provide the relations and analogies that develop my particular modes of thinking, and I am very much aware that my actions as an agent within these programs and of the university maintains the institutional frame itself, while at the same time dismantling the program. I am indeed propelled toward the productive tension between area studies and comparative literature, which in some respects produced the current conditions that are so very conducive to the rise of world literature, although this is an issue for both solidarity and mistrust (Spivak 7-8).

What does this mean for students of comparative/world literature, at both undergraduate and graduate levels? My pedagogical work prompts my students to eschew (or question, or strive to be active in) indistinctive classroom settings or, to borrow from Paulo Friere, resist a high stakes "banking concept of education" that moulds passive learners (71), which is much like the interminable credit card booths on nearly all campuses in Canada-these banking concepts mould passive debtors. What if I take this same potentially threatening passivity from the "banking" undergraduate classroom and overlay it on comparative/world literature? I see forms of interdisciplinary research in crisis, but I also see tremendous room to gamble on change in meaningful, integrative, creative, and dynamic ways. Just as my students become active and risk eschewing their own passivity, I feel the inventions of spring in the midst of our scholarly winter. exists in the same administrative college but is not classified as humanities but as a social science, although it has frequently cross-listed sections with humanities disciplines. The divided loyalties and Byzantine means of organizing labour across these divisions are formidable. They also frequently confront legal and institutional differences between the two countries, particularly with regard to labour practices for the adjunct faculty for whom I am responsible, as well as differences between the university's colleges, which can offer coursework in the same disciplines but with differing college affiliation for students.

Negotiating choice across these divisions is often complex and elides the individual and local exercise of reason in favour of deferring to authority, which has the great possibility of alienating all parties involved from their labour, including the administration. Hence, risk-taking and gambling become common in order to preserve rational autonomy and to negotiate mutually acceptable resolutions between parties who are both compelled through an unfair constriction of choice toward decisions that may embody deference while eliding deeply held mutual goals, most expressly the pacific agenda and intervention implicit in a transnational education that regards intercultural solidarity as the basis for mutual relations and ethical engagement with others (while overtly serving a pro-American, capitalist ideological agenda inclined to appeasement of the social status quo rather than genuinely progressive transformation). It is a high ambition of unity to achieve through an institution and social system fraught with division, and I struggle in it between alienation and solidarity. Choices are indeed gambles, yet lowrisk decisions would bar the outcomes for which the enterprise was ostensibly begun. 
By gambling, we are not calling up any specific gambler (from Dostoevsky to James Bond), although personal debt may resonate with many in the academy, and debt is indeed very often the matter of capital and professionalization in Nealson's sense $(3-4) .^{10}$ Some form of interpellation lures us into a gambler's decision-making scenario: we want to win. Further, we want the gambler to win for us. Throughout each play's micro-negotiation, the gambler will continue to ask him or herself, "What have I got to lose?" Many prefer to play it safe in a scenario in which no one wins and no one loses. This points to a problematic binary: the falsely adversarial link between winning and losing. More importantly, we also know that the house always wins in an unfair negotiation of choice with the gambler, or, more directly, the university as an institution always continues on despite the struggles and choices negotiated among the faculty, administrators, students, and staff in relation to external institutions ranging from governments to transnational capital.

\section{University Thinks, University Does}

In what ways have other people understood the divided or paradoxical thinking of departments and institutions? How are the variously segregated or discordantly unified disciplines in the humanities and the universities, faculties, departments, and programs that house them of two (or more) minds? How do we recognize a public face and private face, anima and shadow, ego ideal and id, or mission statement and praxis? Put another way, what are the conflicts between how the humanities think, in Douglas's sense, and what the humanities $d o$, in Jeppesen's? We propose that this divided mind is endemic, often doing in conflict with thinking, although interpretive opportunities exist in these moments of institutional parapraxis. The truth slips out in this faulty function. Moreover, one of the crucial functions of the university, mentorship, is deeply troubled by these conflicts between thinking and doing, so that, in many respects, the contraction of mentorship and the institutional imposition of barriers to mentorship is symptomatic of larger struggles. This may be seen in a wide range of institutional pressures and procedures: evaluations of untenured instructors in the teacher-student relationship; time pres-

10 Nealson approaches the "matter" of poetry as "larger and more encompassing than any single writer's corpus" (1) in which the professionalization of literary criticism has pushed in a contradictory, lyrical direction for interpretation. Like Nealson, we look for the protagonist that is too grand to be contained in a single author's works (as in the Arthurian "Matter of Britain" in his example), although we query if debt may serve as this "matter." 
sures that diminish the mentorship possible between graduate student and supervisor; job market pressures that redirect the attentions of ABD and postdoctoral students; the asymmetrical power in the relationship built between continuing versus adjunct, sessional, limited-term faculty, or non-tenure earning faculty; the administrative tenure review process that may inhibit the mentorship between junior and senior faculty; the management curtain between faculty and administration; and the widely ignored punctualization of non-academic staff in the quotidian life of a department. We take, below, a sample of responses to these conflicts in order to survey the contemporary scene and the conflicts among its doing, making, and thinking.

Marie E. Cotera offers a direct approach to two keenly felt and intimate concerns within the humanities and the lives of faculty in their respective institutions: the roles of race and gender in tenure reviews. She contends doing is in conflict with thinking, and hence alienation is inevitable amidst the institution's coherence and stability:

Scholars of color understand that the tenure process cannot exist outside of politics, and that a value free assessment of the "quality" and "excellence" of their scholarship is necessarily affected by the kind of work they do, and especially the kinds of communities it serves.... [B]y the time I received my PhD from Stanford, I felt battle-ready, having witnessed the various ways, both overt and subtle, that the university machine relentlessly ground down junior faculty of color until they were either docile citizens of the academic-industrial complex or psychologically damaged.... We are all very familiar with the old "revolving door" concept of diversity enacted at elite institutions.... [T] he hiring process is a numbers game pure and simple, a bid to keep our universities looking "diverse" on paper while never really shifting the center. $(329-30)^{11}$

Although grim and certain to be contested by some, the conflict between thinking diversity while doing uniformity and derogating division is widespread and moves beyond race. What can such a parapraxis reveal about the institutional unconscious? Cotera's interest in the university's self-

11 Although it does not directly relate to our argument here, Cotera's other comments must be included: "My own mentor, a brilliant woman of color, was so unnerved by the insidious political manoeuvrings around her tenure case that the whole process likely contributed to her tragic suicide" (330). The potential for anomie and its most alienating effects is significant, even if we seldom speak of it. 
censored bias is the obvious focus, but it is equally certain that this form of conflicting discourse extends further and indicates conflict between winners and losers in our gambles despite a strong sense of collegial solidarity. The university is of two incompatible minds: one thinking and one doing, and hence our choices are always being made in the passive voice with no subject. The doing of exclusion reveals the self-censored discriminatory desires beneath the thinking of diversity.

Kaltefleiter and Nagel are likewise spirited in drawing attention to the internal inconsistencies of the academy, which follow a kindred pattern in their analysis:

While the academy is often touted as a space that encourages the free and unfettered pursuit of research and inquiry, professors ... who challenge dominant ideologies and paradigms and engage in political action realize that pursuit of their teaching, research, and causes may come at a high cost, such as manifest in denial of promotion, unfavorable working conditions, intrusive surveillance, and other forms of intellectual threat and containment. (40o)

Based on this, they make a more limited argument that merits expansion:

Universities ... function as an "ideological state apparatus" by which the capitalist system perpetuates its norms and values in order to smoothly reproduce itself.... Like Althusser, Bourdieu views the university system as integral to the (re)production of capitalist values, ideologies, and imperatives, such that "higher education" is designed not to cultivate knowledge and autonomy but rather to instruct students and professors how to labor in a market-dominated world. (400-01)

Here is a pedagogical assessment of the work done in the classroom, for which deeply held beliefs about the thinking of the institution and the individuals (and structures) that comprise it may emerge in a stunning conflict with the doing of its work. The same problem is also at the heart of Readings's reconfiguration of how we understand the university and institutions that serve the transnational interests of capital rather than the traditional interests of national culture. Much earlier, Herbert Read anticipated such problems and firmly bound "Culture," in the sense of a thing obtained or added, having always been deeply bound to capital (12). ${ }^{12}$ We intellectually embody and teach the ethos of the Enlightenment,

12 Read launched his critique from the discussion of culture as something obtained or added to products by Eric Gill, such as the addition of "culture" to a product 
even today, while frequently constructing a climate and labour relations (including those between faculty and student intellectual labour) that are exploitative and authoritarian. We extol rational thought and the necessity for self-determination in decision-making based on the degree to which an individual may exercise reason, and in the same breath we establish relations and institutional conformity of a constraining, directive sort that seek to subordinate the exercise of reason to structure, form, and tradition. Amidst contradictions, we seek engaged excellence, independence in equity, and accountable academic freedom.

This position leads Kaltefleiter and Nagel to further reconsider the role of peer review and blind review in the research component of scholarly work and its value in consideration for tenure (itself a function of tradition and authority that contradicts yet is necessary to the enlightenment function of the university and its role in the nation state). This is to say, we value tenure for its protection of the free exercise of reason while it is at the same time a process deeply entwined with authority and myth.

The tenure process, as with other kindred processes for ensuring the free exercise of reason within the university, is assuredly the centre of our own enlightenment values and assertion of reason over obedience. Kaltefleiter and Nagel find precisely the opposite:

Today radicalized curricula are limited and those who speak out are often silenced through punitive personnel decisions, above all by denial of tenure.... Due to its secret committee elaborations on the candidate by a "jury of peers," it is akin to a criminal trial process, where the candidate has to make a best case in order to win approval ("acquittal"). Yet the crucial difference to a trial is that the academic applicant is represented without counsel in the review process. At many institutions, it is marginalized individuals-e.g. political radicals, women, people of color (women of color especially), gay, lesbian, transgender people, and those with disabilities-who find themselves under the most intense scrutiny. (404)

Their focus is strictly limited to the tenure process. Nonetheless, behind it is a far more urgent call for freedom of expression without reprisal by

to make it more palatable (say, a sauce to otherwise stale fish). In turn, Read and Gill were taken up by Okot p'Bitek to critique the statist interventions in producing culture through a ministry of culture in Uganda (16). In all three, the distinction between culture as something lived as opposed to something added or acquired is bound deeply to the emergence of capitalist economies such that the two are indistinguishable. 
those who are most at risk and most deeply dominated by institutional hierarchies at precisely the time in their careers when the innovative and free exercise of reason is ostensibly supported and valued to the highest degree: limited-term, sessional, and graduate faculty. The young (and not so young) of the modern university face an unprecedented level of hegemonic influence and coercion at the time in their lives when they are most capable of (and most needed to) exercise reason freely. The protections of tenure, and the lack of solidarity between the tenured and untenured, serve the interests of neither group and function as a destabilizing force. Increasingly migratory faculty, authoritarian forms of accountability, litigation, and the pressure to abolish tenure in more and more schools lead to instability in the form of reduced institutional memory, resources wasted on repeated recruitment, and even the time-consuming trouble of grade appeal and deferrals by students through instructors who are only temporary members of the institution. Instability in the labour market destabilizes the community as an institution by robbing it of continuity, both real and imagined. Meanwhile, protection of tenure while the tenured endorse lecturer or fixed-term positions and labour uncertainty also leads to greater instability through the discouraging of the innovative energies of the younger members of the institution who are most directly in touch with the shifting nationalist ambitions of the university and the emergence of new technologies and culture. ${ }^{13}$ A third party concomitantly centres on the administrators who reintroduce a hierarchical class system in which lines of communication are stymied but might otherwise permit clarity concerning employment, evaluation, qualifications, and stability. For fear of administrative reprisals, peer group decisions are increasingly less collegial, more secretive, and unlikely to be documented in written records recoverable through FoIP. ${ }^{14}$ These individually protective actions lead to a collective loss of security that might otherwise have been avoided through the solidarity Douglas speaks to at the beginning of this article.

13 Institutions are increasingly less interested in grooming faculty and instead appear to wish to hire the "resplendent, dream-born figures of the Olympians" (Nietzsche 23) or new faculty who will leap like Athena, fully formed from the head of Zeus with no periods of growth and development and, least of all, no periods without external funding gained through acquiescence to the ideological, methodological, and disciplinary institutional thinking of the university. Such is how we seek innovation and the production of new economies of knowledge.

14. Junior administrators are often advised, as are faculty, to say things rather than write them in print such that the evanescent replaces the record in our increasingly monitored and digitized world. To find "plausible deniability" in the everyday dialect of directors, chairs, and deans is stunning yet is clearly linked to the accessibility of records. Contracts, offers, sensitive discussions or 
A debate about the university in this vein, and the humanities within it, draws us back again to the conflict between aims and actions, or like Horkheimer and Adorno's sense of enlightenment, the alienation inherent in enlightenment that then requires enlightening. Adorno and Horkheimer attempt to reconfigure Kant's idea of the Enlightenment: "while trying to abolish superstition and myths by 'foundationalist' philosophy, it [the Enlightenment] ignored its own 'mythical' [irrational] basis. Its strivings towards totality and certainty led to an increasing instrumentalization of reason" (Horkheimer and Adorno 8). In effect, they are concerned with the conflict between thinking and doing in the Enlightenment and in particular its function within the nation state. In their view, the Enlightenment itself should be enlightened and not presented as if it were a myth-free means of accessing the world. In other words, enlightenment thought values reason so highly that it engenders reason with a seed of totalizing thought that germinates rapidly, to the point that enlightenment thinkers would no longer notice the emotional and irrational components of their emphasis on reason. Here the original phrasing is useful:

myth turns into enlightenment, and nature into mere objectivity. Men pay for the increase of their power with alienation from that over which they exercise their power. Enlightenment behaves towards things as a dictator toward men. He knows them in so far as he can manipulate them. The man of science knows things in so far as he can make them. In this way, their potentiality is turned to his own ends. (Horkheimer and Adorno 9)

The crux here is their assertion that "Men pay for the increase of their power with alienation from that over which they exercise their power" (9), and their example of the scientist applies equally well to the humanist, lecturer, or literary reader. In a simplified sense, by exerting power over a friend, we become alienated from friendship. The authoritarian society germinates anomie. By dominating the material to which we stand in relation, we become alienated from it and falsely behave as if we were not a part of the material world. Adorno and Horkheimer saw this mistake as the consequence of the Enlightenment's rationalist ideology. For

negotiations, the processing of appeals, reprimands, evaluations, or administrative input on academic matters or tenure reviews are all likely to exist only in final forms without the paper trail of FoIPable emails, memos, or letters. The opposite tendency is toward hegemonic institutional control, such as requiring the exclusive use of institutional avenues of communication and data storage. 
them, amidst the Second World War and the Frankfurt School in exile, the Enlightenment itself was an irrational force driving Western culture to idealize rationality even though it is not the totality of human experience and excludes our material existence as material. Humans are both rational and irrational, and we are unlikely to be wholly one or the other. Hence, the move to elevate reason in the Enlightenment was itself part of a myth or worldview that dominates how we go about living and alienates us from ourselves and in doing so incurs great costs to others (which they may or may not accept as a debt to us). The cost of this myth was alienating man from nature by aligning nature with irrationality and the domination of nature as reason itself. This myth lives well in our rational institutions, and we fervently retell this myth in conflicted doings and thinkings, both on manicured natural spaces on campus and in manicured minds trained to perambulate only through the administrative pathways.

Our alienation in conflicted thinkings and doings may be more obvious where pedagogy and research meet. The university has increasingly relied on sessional or adjunct labour, especially in the humanities, as well as an increase in fixed-term teaching contracts and non-tenured lecturer positions in order to meet the demands of teaching. In some instances, this reliance is compounded by the segregation of portions of the student body, such as international students, into separate campuses or buildings. The result of segregation can result in principally graduate or undergraduate campuses in the same institution, satellite campuses, or the division of programs leaving one portion accredited and another not. It is not uncommon to find courses from any particular department being offered to international students by instructors not affiliated with the department, and this is particularly so in language-intensive and humanistic disciplines. The global classroom exists in disciplines dependent on globalized revenue streams, such as business (which has increased its proportional enrolments in Canadian universities almost exclusively through international students from 1992 to 2008 [McMullen np]), but how many honours seminars in the humanities reflect the increasingly international makeup of Canadian universities, particularly in British Columbia? If not, why? These students may be taught in a different location, and in many cases, especially if their campus is offsite or not in Canada, they cannot even transfer into the home campus of their own institution, and hence they remain invisible. ${ }^{15}$ This engenders alienation, but it does so with a

15 Despite our trepidations over the potential for educational imperialism and apologist Liberalism, this is one strength of Fairleigh Dickinson University in Vancouver as well as Simon Fraser University in Vancouver, Burnaby, and 
surprising profusion. Students are alienated from their studies, which have become an instrument for other aims and are not as often seen as having their own intrinsic value. The exploited labour of adjuncts, contract workers, or non-tenured teaching faculty in lecturer positions leaves scholars excluded from scholarship and increases teaching to a workload that precludes personalized work. However, apart from alienation, these divisions also generate a crushing problem - the least academically valued scholars become the intellectual core of the university's transmission of knowledge to new generations and the de facto public face of academia to students discovering it for the first time. In contrast, they are the least supported in this role. Adjunct faculty may face institutional barriers to research funding or applications for scholarly support, students will have the least contact with the most valued and experienced scholars during the formative years of their studies, and research-active faculty are set in a competition that discourages the creative charge provided by innovative pedagogy and the student-teacher relationship. Such conditions are less than ideal for all three groups involved, even if they feel they are pursuing their own best interests in the moment.

Jessica Schagerl, from the subject position of a graduate student, is remarkably (and admirably) bold in sketching the graduate student, junior faculty, senior faculty, and administration divisions that hold true amidst a discourse of solidarity and an institutional practice of equality demonstrated in shared labour and teaching as well as research responsibility and expectations. For Schagerl, the effect is bound to the matter of class, despite the thwarted intentions of the powerful that reveal their own alienation from doing as they think:

Most graduate students hold a precarious position as a result of the lack of any substantial investment by funding agencies in their research and work-even though in order to secure a tenure-track job they are asked to be just as productive as, if not more so than, seasoned colleagues.... Teaching fellowships

Surrey. Students belong to the institution rather than to a particular campus, and mobility is generally unrestricted. It is not so for many other institutions that maintain overseas or even close to home satellite campuses, often with parallel departments that may not share the accreditations of the main campus and as often as not prohibit students from moving between campuses or even requesting transfer credit within their own program from one campus to another. The segregation of international students under the euphemism of diversity, however, calls out for further analysis, such as critiques by CAUT of Fraser International College and International College Manitoba run by Navitas International ("Probe" A5, A9; "Board" A1, A8). 
or contracts, for instance, can easily fall under the rhetoric of professional development but end up being convenient ways for universities to exploit junior faculty under another guise, forcing a continuation of the transient life of a graduate student but for someone with a PhD in hand. The scarcity of full-time tenure track employment is often a greater concern to people caught in these positions than the future of research models. (98-99)

The insistence with which she refers to junior faculty is telling and damning since our doing in the university assumes the viability of such a position with graduate students not infrequently teaching senior level courses and adjunct faculty very frequently doing so. If we stop to reflect, our thinking moves in precisely the opposite direction: through limitations on access to research funding, release time, institutional affiliation for research purposes, and often even matters as simple as library access and electronic scholarly databases or, outside the humanities, lab space and facilities. ${ }^{16}$ From this basis, she argues, "ssHRC promotes a future-oriented discourse, especially through its core values of 'learning' and 'Building Capacity' (Knowledge Council 7). Yet there is a substantial gap between SSHRC's conscious acknowledgment of the role of junior scholars and its planning in a practical way for a future that will embrace us" (Schagerl 10o). Implicit in our placement of Shagerl's comments on graduate students and postdoctoral fellows is a return to adjuncts and junior teaching faculty here, as well as untenured lecturers. We do not value them as equals to continuing faculty and exclude them from institutional processes. We also frequently employ them to teach the most students, and among these the most impressionable, particularly international students, whose presence on our campuses reflects the new and strategically valued role of the university as it returns to a space of nationalist cultural interests and a gateway to immigration, a role the humanities has entered through a policy of appeasement. Our distrust does not easily reconcile with our actions of solidarity-it grants the labour pool of academia no status while concomitantly relying on the same group's expertise and essential role in the intellectual life of the university as well as the future of national culture. Those whom we trust the least with institutional identity and stability we entrust in the same moment with the most sensitive and still-uncertain execution of the university's function. Is this an effective exercise of reason?

16 How does one publish during the summer break when institutional privileges are often immediately revoked and the threat of unemployment hovers? Very clearly, the institutional doing speaks contrary to the thinking. 
We regard this movement as the persistent globalization of an institution, the university, that formerly served the interests of nationalist culture. The movement operates in tandem with increasing fiscal pressures on Canada's public education system that compel the humanities to transition from a space to a series of relations or reputations, and from a means of recreating particular national cultures to a mechanism in the economic process of globalization. The humanities now serve competing interests, as seen in immigration, which serves both transnational capital and the nation state (if there remains any appreciable difference between the two). Our institutions struggle under budgets that leave faculty positions vacant and force the students who pay the most, international students, to increasingly study with instructors who are paid the least: sessional and contract faculty. And they do so in the courses for which they need the most sustained contact in order to achieve their future goals. ${ }^{17}$ Now, we must fulfil our obligations to students, teach, and conduct research in an institution that is struggling to shape transnational migration in the discourse of nationalist interests while serving a second master, transnational capital, which abhors nationalist protectionism, even while the "chalk and talk" humanities prove their budgetary value.

\section{The Return of the Gambler}

This is all to say, we gamble each term, although we must learn to elide winning and losing. We wager how well a given text will go over, and we sometimes cast the dice early in the game. But what are the stakes for students? What do students calculate or negotiate each time they commence a new term of assignments and prof shopping, especially in their humanities courses, in which rapport with and interest in a professor are vital? They too wager on classes, by endeavouring to balance their study, work, and hobbies (or life activities) with the expectations we place on them and with their own genuine intellectual curiosity: a high-risk ambition in professionalized education. Genuine curiosity risks late penalties or wandering too far afield from the proscribed course of readings or disciplinary focus. Most students will, if at all possible, choose low-risk situations with more certain paths to successful completion. Moreover, the

17 For example, the $\mathrm{BC}$ provincial government and the federal government are pursuing a sizeable increase in international students through ongoing studies of maximizing capacity and strategies for recruiting and expediting the applications for international students regarded primarily as part of a migrating labour pool following the pathways of capital established by provincial and federal agreements on immigration policy and postsecondary funding priorities. For a more detailed commentary, see note 7 . 
university is a risk-averse institution, and we already know that students tend to elide learning for winning in high-stakes scenarios. Undeterred by these realities, we continue to play for keeps when we know it runs contrary to our best interests: a make-or-break evaluation, feedback only on a final product, single-stage competitions in a winner-takes-all competition, and so forth. We do these often in the university while talking about the opposite-this is how our praxis transforms and with it our institutional thinking.

Everywhere we turn in the university, risk and speculation lurk. Fiercely and feverishly, we regress, regroup, and plan our defence, all of which engenders the tragedy. In turn, for graduate students, these stakes assume the form of various grant applications, letters of evaluation, letters of support, lecture preparations, feedback and evaluation, conference attendance, and finally the reason we became interested in academia in the first place: scholarship. If we don't get it done, we're not competing; and if we're not competing, are we then not academics? In fact, as we see it, the publish or perish paradigm perpetuates just this myth, and we quickly adopt and adapt in pursuit of reason but end in alienation. Publish or perish is only a myth, one that finds us competing aggressively and secretly against or with colleagues as we battle for funding rights, teaching relief (primarily for those who teach the least), administrative support, teaching staff, and administrative funding for the department, unit, college, school, or program. This spirit of competition is toxic: it compresses-perhaps deadensthe very spirit of research and collegial enterprise in the humanities that inspired us in the first place. It elides the open source revolution implicit in academia (Ogle 27-29) and replaces it with a constant emphasis on reaching higher and higher for money, stature, and justification orders. The risk-averse environment renders competition petty and ambitions pedestrian, just as excellence atrophies and the engaged institution gives way to alienation. What other paradigm might we think and enact?

Low-stakes learning, which is uniquely possible and productive in the humanities, as in our undergraduate pedagogy example above, is meant to foster critical thinking, exploration, participation, explanation, retention of ideas, personalization and reflection of content, and creativity and further develop student-instructor interactions through meaningful mentorship. Rather than avoiding risk, it permits high-risk intellectual engagement via low competition and by temporarily suspending the false adversarial binary of winners and losers in risk taking and evaluation. To gamble is not to win or lose but, rather, to dare. In turn, daring may bring benefits

110 | Parker and Gifford 
to all, and, if not, it hardly makes losers by virtue of not materializing immediate gains: the stakes are low.

\section{Conclusion}

Having recently been a graduate student, I can For junior faculty or young administrators, there speak to what others often keep silent: our sense of the unspoken expectation that we complete our coursework, teach a little throughout, take part on student council, teach ourselves to edit papers, write article reviews, apply for every grant possible (a task that consumes days and weeks if there is no mentoring to be found), learn the language and syntax of grant proposals, start a journal, host a conference or two or three, publish articles, earn enough to live on and rely on debt for the difference, find time to write a dissertation (and learn the syntax of that language as well), only to teach ourselves how to apply for jobs. are institutional paradigms or best practices to discover, often after inadvertently violating them. There are student-centred initiatives to propel in order to fulfill expectations of service (presumably for service's sake rather than any particular initiative), the demonstration of scholarly excellence, and the cultivation of independent creative thought with the ambition of securing funding via channels that value conformity to established paradigms or systems of evaluation. The problem is whether these are institutional or self-directed thoughts and activities or, rather, if we create a self by doing these things over and over quickly enough.

Some may contend, "What's so bad about that? That's what it was like when I was a student. We had to survive and figure it out on our own." That is the crux of the problem this article addresses. This intense individualization of studies and scholarly labour, as a dilution of solidarity, is at heart the problem we wish to combat. Further, beyond individualization, it still means graduate students being pitted against faculty, where graduate students are expected to leap from graduate training to faculty performance, and of junior faculty against senior faculty, and faculty against administration, and academic administrators against non-academic staff and administrators. We do contrary to our thinking and make a product that satisfies neither. We too quickly reduce to a binary what can become a meaningful trilogy. We therefore must exhort solidarity, daringly!

\section{Works Cited}

p'Bitek, Okot. "What is Culture?" Artist, the Ruler: Essays on Art, Culture, and Values. Nairobi: Heinemann Kenya, 1986. 13-18.

"Board and Senate Bypassed in Navitas Deal/Une entente négociée sous le voile du secret avec Navitas." CAUT/ACPPU Bulletin 55.2 (February 2008): A1, A8. 
British Columbia. Ministry of Advanced Education. British Columbia's International Education Strategy. Victoria: Ministry of Advanced Education, 2012. Web. 14 July 2012.

Canada. Citizenship and Immigration Canada. Canada-B.C. Immigration Agreement, 2010. Web. 12 July 2012.

Cotera, Maria E. "Women of Color, Tenure, and the Neoliberal University: Notes from the Field." Academic Repression: Reflections from the Academic Industrial Complex. Eds. Anthony J. Nocella II, Steven Best, and Peter McLaren. Oakland: AK Press, 2010. 328-36.

Douglas, Mary. How Institutions Think. Syracuse: Syracuse UP, 1986.

Fleck, Ludwik. Genesis and Development of a Scientific Fact. Eds. Thaddeus J. Trenn and Robert K. Merton. Trans. Fred Bradley and Thaddeus J. Trenn. Chicago: University of Chicago Press, 1981.

Horkheimer, Max, and Theodor Adorno. Dialectic of Enlightenment. 1979. Trans. John Cumming. New York: Continuum, 1997.

Jeppesen, Sandra. "do / make / think: anarchy and culture." Culture and the State: Alternative Interventions. Eds. James Gifford and Gabrielle Zezulka-Mailloux. Edmonton: CRC Humanities Studio, 2004. 64-75.

Kaltefleiter, Caroline K., and Mechthild E. Nagel. "The Carceral Society: From the Prison Tower to the Ivory Tower." Academic Repression: Reflections from the Academic Industrial Complex. Eds. Anthony J. Nocella II, Steven Best, and Peter McLaren. Oakland: AK Press, 2010. 400-14.

McMullen, Kathryn, and Angelo Elias. "A Changing Portrait of International Students in Canadian Universities." Education Matters: Insights on Education, Learning, and Training in Canada. Tourism and the Centre for Education Statistics Division. Statistics Canada. Ottawa: Statistics Canada, 2011. Web.

Nealson, Christopher. The Matter of Capital: Poetry and Crisis in the American Century. Boston: Harvard UP, 2011.

Nietzsche, Friedrich. The Birth of Tragedy and Other Writings. Eds. Raymond Geuss and Ronald Spiers. Cambridge: Cambridge UP, 1999.

O’Driscoll, Michael, and Edward Bishop. "Archiving 'Archiving.' EsC: English Studies in Canada 30.1 (2004): 1-16.

Ogle, Matthew. "Hackers, Humanists, and Intellectuals: Lessons from the Open Source Revolution." Culture and the State: Alternative Interventions. Eds. James Gifford and Gabrielle Zezulka-Mailloux. Edmonton: CRC Humanities Studio, 2004. 24-43.

112 | Parker and Gifford 
"Probe Questions International Recruitment/Remise en cause du recrutement international." CAUT/ACPPU Bulletin 57.9 (November 2010): A5, A9. Web.

Read, Herbert. “To Hell With Culture” To Hell With Culture. 1963. London: Routledge, 2002. 10-36.

Readings, Bill. The University in Ruins. Boston: Harvard UP, 1996.

Schagerl, Jessica. "Taking a Place at the Table." Retooling the Humanities: The Culture of Research in Canadian Universities. Edmonton: University of Alberta Press, 2011. 95-111.

Spivak, Gayatri Chakravorty. Death of a Discipline. New York: Columbia UP, 2003.

"University of Toronto Campus Groups Start Alternative Governance Structure." САUT/ACPPU Bulletin 58.2 (February 2011): A5. Web. 